\title{
DECISÕES JUSTAS EM PROCESSO ADMINISTRATIVO: HÁ GARANTIA DE IMPARCIALIDADE SEM GARANTIA DE INDEPENDÊNCIA?
}

\author{
FAIR DECISIONS IN ADMINISTRATIVE PROCESSES: IS THERE \\ IMPARTIALITY GUARANTEE WITHOUT INDEPENDENCY GUARANTEE?
}

${ }^{1}$ Marlyus Jeferton Da Silva Domingos

\section{RESUMO}

O princípio do devido processo legal deve também ser observado nos processos administrativos. Considerando que a decisão de uma autoridade administrativa por vezes pode refletir um verdadeiro julgamento, o artigo tem por objetivo geral analisar a existência de previsão normativa para a imparcialidade e a independência de um julgador e como objetivo específico identificar a possível relação entre elas. Além da pesquisa bibliográfica, foi utilizada como metodologia a observação participante, uma vez que o autor desempenha a função de julgador de litígios em processos administrativos fiscais na Secretaria de Fazenda do Estado do Rio de Janeiro.

Palavras-chave: Devido processo legal, Independência, Justiça administrativa

\begin{abstract}
The principle of due process of law must be observed in administrative processes. Whereas the administrative authority's decision can sometimes reflect a true judgment, the general objective of this article is analyzing the existence of rules for impartiality and independency for a judge and the specific objective is recognizing the possible relationship between these technical features. Beyond the literature research, the participant observation was used as a method to prepare this article, since the author judges disputes in tax administrative processes in the Finance Secretary on the State of Rio de Janeiro.
\end{abstract}

Keywords: Due process of law, Independency, Administrative justice

\footnotetext{
${ }^{1}$ Possui Mestrado profissional em andamento em Justiça Administrativa pela Universidade Federal Fluminense, UFF - RJ, (Brasil). E-mail : marlyusppgja@gmail.com
} 


\section{INTRODUÇÃO}

O devido processo legal (due process of law), previsto expressamente no art. $5^{\circ}$, LVI da Constituição da República Federativa do Brasil (CRFB), é princípio constitucional que abrange vários outros necessários à obtenção de uma decisão justa, tais como os expressos no inciso LV do mesmo artigo da CRFB (contraditório e ampla defesa).

Este último inciso traz outra importante informação: o devido processo legal não está limitado aos processos judiciais, devendo também estar presente nos administrativos.

Além disso, é cediço que as decisões em um processo administrativo com frequência afetam os direitos de seus interessados e, por isso, têm regras básicas previstas em normas legais.

Considerando que a decisão de uma autoridade administrativa por vezes pode refletir um verdadeiro julgamento, o presente trabalho tem por objetivo geral analisar a existência de previsão normativa para a imparcialidade e a independência de um julgador e como objetivo específico identificar a possível relação entre elas.

Haveria garantia de imparcialidade na decisão em um processo administrativo sem uma garantia de independência da autoridade administrativa competente para este ato?

Para chegar aos objetivos propostos o autor entendeu necessário demonstrar uma evolução histórica da relação entre a imparcialidade e a justiça, identificar a constitucionalidade das garantias de independência de um julgador, verificar uma possível coexistência entre as garantias de independência e a imparcialidade e verificar a necessidade de aplicação dessas garantias aos julgadores presentes na administração pública.

Em relação à citada evolução histórica, foi abordado o aparecimento do Estado e a decorrente necessidade de entregar a decisão em litígios para um julgador competente, com o objetivo de deixar no passado a predominância da força física e alcançar um resultado justo, bem como as diferenças entre as características de um julgador desde a Mesopotâmia, passando pelos períodos da Idade Média e do Renascimento, até os dias atuais.

Em relação à identificação da constitucionalidade das garantias de independência de um julgador e à verificação de uma possível coexistência entre as garantias de independência e a imparcialidade, foram analisados os artigos 95 e 99 da Constituição da República Federativa do Brasil. 
Tal análise foi considerada importante para o desenvolvimento do presente artigo por verificar que o legislador constituinte, ciente da necessidade de impedir limitações espúrias ao poder de decisão, procurou fixar garantias ao Poder Judiciário e aos Juízes, aqueles que detêm a função típica de julgamento.

Em relação à verificação da necessidade de aplicação dessas garantias aos julgadores presentes na administração pública, foi abordado que o legislador infraconstitucional não acompanhou a lógica do constituinte em relação à previsão de garantias de independência, criando um ambiente propenso a falhas no que se refere ao cumprimento do devido processo legal em sede administrativa.

A hipótese principal do autor é a impossibilidade de garantir um julgamento justo quando não há previsão normativa de garantias de efetiva independência para o julgador.

A justificativa principal do presente artigo é a necessidade de demonstrar a existência de possíveis falhas que dificultariam a implementação do devido processo legal na administração pública, trazendo, assim, uma colaboração para a implementação de uma efetiva justiça administrativa.

Importante destacar que a ausência deste devido processo legal pode trazer efeitos desiguais para as partes que desejam questionar as decisões das autoridades administrativas, uma vez que a necessidade de alcançar um resultado justo, tendo acesso ao poder judiciário, acarretaria no aumento de custos, por vezes insuportáveis para um determinado grupo de administrados.

As metodologias utilizadas para a confecção deste artigo foram a pesquisa bibliográfica e a observação participante.

Esta última se dá pelo fato do autor trabalhar na Secretaria de Fazenda do Estado do Rio de Janeiro, na função de Auditor Tributário, competente para o julgamento de litígios em processos administrativos fiscais.

\section{DESENVOLVIMENTO}

Para analisar a existência de previsão normativa para a imparcialidade e a independência de um julgador, bem como identificar a possível relação entre elas, torna- se necessário demonstrar uma evolução histórica da relação entre a imparcialidade e a justiça, identificar a constitucionalidade das garantias de independência de um julgador, verificar uma 
possível coexistência entre as garantias de independência e a imparcialidade e verificar a necessidade de aplicação dessas garantias aos julgadores presentes na administração pública.

\subsection{A Imparcialidade e a Justiça: Evolução Histórica}

Com o aparecimento do Estado, decorrente de um pacto social (ROUSSEAU, 1999), surge a necessidade de entregar a decisão em litígios para um julgador competente, com o objetivo de deixar no passado a predominância da força física e alcançar um resultado justo.

Porém, essa busca pela justiça, como a entendemos atualmente, nem sempre era uma das funções desses julgadores. Em sua obra, História, Figueira (2002, p. 28) ensina que, em relação ao respeito dos julgadores da Mesopotâmia ao Código de Hamurabi, "muito diferente dos códigos atuais, os juízes mesopotâmicos não eram obrigados a seguir seus artigos; sua principal função era mostrar a justiça e o poder do rei”.

O julgador, na época, era uma espécie de longa manus do Rei. A imparcialidade, em especial quanto aos litígios entre o indivíduo e o Estado, era claramente inexistente. A noção de direito e justiça se limitava ao cumprimento das ordens reais. Tal situação perpassou por toda a Idade Média, acrescentando, nessa era, a característica divina à vontade do Rei.

Com o Renascimento, a noção de direito e justiça começa a migrar do divino ao racional. É o que se entende da obra Introdução ao Estudo do Direito: Técnica, Decisão, Dominação, do autor Tercio Sampaio Ferraz Júnior (2003, p. 65), quando o autor menciona que "a partir do Renascimento, o direito irá perder progressivamente seu caráter sagrado. E a dessacralização do direito significará a correspondente tecnicização do saber jurídico.”

Racionalizado o direito, surge a teoria tripartite da separação dos poderes, capitaneada por Montesquieu (1995, p. 118):

A experiência mostra que todo homem que tem poder é tentado a abusar dele. Para que não se possa abusar do poder é preciso que, pela disposição das coisas, o poder faça parar o poder. Uma Constituição pode ser de tal modo que ninguém será obrigado a fazer coisas que a lei não obriga, nem será impedido de fazer as que a lei permite. Para o cidadão, a liberdade política é esta tranquuilidade de espírito que provêm da opinião que cada um possui de sua segurança.

E, para que se tenha essa liberdade, é preciso que o governo seja de tal modo que um cidadão não possa temer outro cidadão. (MONTESQUIEU, 1995, p. 118) 
Desde então, os arbítrios dos Reis começaram a ser questionados, já que o julgamento passou a ser característica típica de um poder (Judiciário), independente dos demais. A lei passa a ser a referência principal de um julgador, com vistas a inibir abusos de autoridade e buscar a igualdade formal entre os homens.

Vale observar que, a partir deste momento, o impedimento para um julgamento imparcial deixou de existir, pois o julgador não era mais um "cumpridor das ordens reais", passando a ter a lei como referência única.

Porém, ainda havia lacunas para se chegar ao que entendemos atualmente como julgamento imparcial, uma vez que, até então, o judiciário seria um mero cumpridor das leis escritas, ainda que injustas.

Esse entendimento positivista do Direito, de inspiração Kelseniana, certamente não se adequa ao que atualmente se entende por justiça, busca incessante de um julgador (KELSEN, 1991).As correntes idealistas do direito trataram de enfrentar a questão.

É o que se extrai da obra de Freitas Filho (2003, p. 40-41), Crise do Direito e Juspositivismo: A Exaustão de um Paradigma:

O paradigma vigente é uma construção teórica forjada e consolidada no
decorrer da modernização sócio-econômica do país, entre os anos 60 e 80 ,
e é vinculado ao caráter normativista do positivismo de inspiração
kelseniana. Este paradigma considera o Estado como fonte central de todo o
Direito e a lei como sua única expressão, formando um sistema fechado e
formalmente coerente, cuja pretensão de "completude" despreza, como já dito,
no designativo de "metajurídicas", todas as indagações de natureza social,
política e econômica. (FREITAS FILHO, 2003, p. 40-41)

A Teoria Tridimensional do Direito, de Reale (1994), surge desses enfrentamentos, estabelecendo a ideia de que o Direito tem seus aspectos normativo (ordenamento), fático (efetividade social) e axiológico (justiça), abrindo caminho tanto para Dworkin quanto para Habermas sedimentarem o compromisso entre o Direito e a Justiça, acima do existente entre o Direito e as normas positivadas.

Chega-se, assim, ao entendimento contemporâneo do objetivo do direito e o julgador, finalmente, consegue ter como referência máxima de suas decisões a busca pela justiça e, consequentemente, um comportamento imparcial.

Vale ressaltar que essa busca demanda o conhecimento dos princípios constitucionais vigentes e, para torná-los efetivos, o julgador pode se deparar com uma omissão legislativa, tendo que, se necessário, utilizar costumes de conteúdo praeter 
legem ${ }^{1}$, com base no art. $4^{\circ}$ da Lei de Introdução às Normas do Direito Brasileiro, o qual preceitua que, "quando a lei for omissa, o juiz decidirá o caso de acordo com a analogia, os costumes e os princípios gerais de direito".

Seguindo tal norma, tem o julgador, imparcial, a subjetividade como uma das características marcantes de seu labor, mostrando-se, assim, necessárias algumas garantias (abordadas adiante), para evitar influências externas ao exercício do seu poder decisório.

\subsection{Garantias Constitucionais de um Julgador}

O direito é um conjunto de normas jurídicas válidas e a aferição desta validade depende da existência de um escalonamento daquelas normas. Será considerada válida uma norma jurídica quando puder ser subsumida à outra (hierarquicamente superior).

Este modo de aferição se mantém até encontrar uma norma constitucional, a qual, por ser positivação da vontade do real detentor do poder - o povo -, deve ser a maior referência para a decisão de uma autoridade competente.

O legislador constituinte, ciente da necessidade de impedir limitações espúrias ao poder de decisão, procurou fixar garantias ao Poder Judiciário e aos Juízes, aqueles que detêm a função típica de julgamento.

Constam, pois, na Carta Magna vigente tais garantias, classificadas como institucionais, no artigo 99, ou funcionais, no artigo 95 (SILVA, 2005).

Essas últimas (funcionais), segundo a melhor doutrina, dividem-se em garantias de independência (incisos I a III) e garantias de imparcialidade (parágrafo único), in verbis:

Art. 95. Os juízes gozam das seguintes garantias:

I - vitaliciedade, que, no primeiro grau, só será adquirida após dois anos de exercício, dependendo a perda do cargo, nesse período, de deliberação do tribunal a que o juiz estiver vinculado, e, nos demais casos, de sentença judicial transitada em julgado;

II - inamovibilidade, salvo por motivo de interesse público, na forma do art. 93, VIII;

III - irredutibilidade de subsídio, ressalvado o disposto nos arts. 37, X

e XI, 39, $\S 4^{\circ}, 150$, II, 153, III, e $153, \S 2^{\circ}$, I.

Parágrafo único. Aos juízes é vedado:

I - exercer, ainda que em disponibilidade, outro cargo ou função, salvo uma de magistério;

\footnotetext{
${ }^{1}$ Costumes existentes e prévios à existência de uma norma.
} 


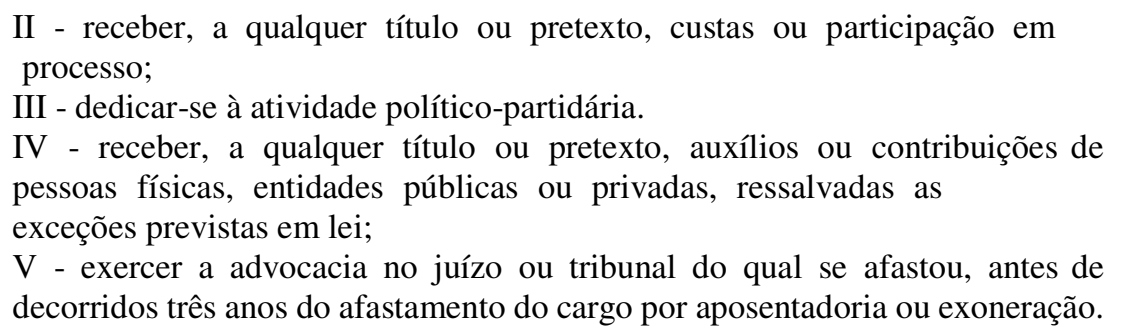

A classificação doutrinária para o parágrafo único, citado acima, merece uma pequena observação: não se tratam de garantias de imparcialidade em listagem numerus clausus $^{2}$, sendo meros exemplos de comportamentos que têm potencial para abalar a imparcialidade esperada de um julgador.

A imparcialidade é conceito intimamente ligado com o julgamento justo, decorrente do princípio do juiz natural, assim entendido por Mendes (2012) e Pacheco (1985), e do princípio da isonomia, assim entendido por Campanelli (2006) e Freitas (2004). Desses entendimentos é possível extrair que a imparcialidade é princípio constitucional implícito.

Vale destacar, também, que as garantias de independência já se mostravam fundamentais desde a nossa primeira Constituição, datada de 25 de março de 1824, onde a ideia ficou adstrita à vitaliciedade, conforme se observa da leitura dos artigos 153 e 155 (in verbis):

Art. 153. Os Juizes de Direito serão perpetuos, o que todavia se não entende, que não possam ser mudados de uns para outros Logares pelo tempo, e maneira, que a Lei determinar.

$[\ldots]$

Art. 155. Só por Sentença poderão estes Juizes perder o Logar.

Na Constituição de 1891 a vitaliciedade manteve-se garantida pelo artigo 57 e, no $\S 1^{\circ}$ do mesmo artigo, surge a garantia da irredutibilidade de subsídios (in verbis):

Art. 57. Os Juízes federais são vitalícios e perderão o cargo unicamente por sentença judicial.

$\S 1^{\circ}$. Os seus vencimentos serão determinados por lei e não poderão ser diminuídos.

A partir da Constituição de 1934, em seu artigo 64 (in verbis), são previstas as três modalidades de garantias:

\footnotetext{
${ }^{2}$ Número fechado
} 
Art 64 - Salvas as restrições expressas na Constituição, os Juízes gozarão das garantias seguintes:

a) vitaliciedade, não podendo perder o cargo senão em virtude de sentença judiciária, exoneração a pedido, ou aposentadoria, a qual será compulsória aos 75 anos de idade, ou por motivo de invalidez

comprovada, e facultativa em razão de serviços públicos prestados por mais de trinta anos, e definidos em lei;

b) a inamovibilidade, salvo remoção a pedido, por promoção aceita, ou pelo voto de dois terços dos Juízes efetivos do tribunal superior competente, em virtude de interesse público;

c) a irredutibilidade de vencimentos, os quais, ficam, todavia, sujeitos aos impostos gerais.

Sem diminuir a importância das garantias funcionais, o presente trabalho tem como um dos enfoques a análise da necessidade de coexistência de garantias de independência e princípio da imparcialidade, conforme veremos adiante.

\subsection{A Necessária Coexistência d e Garantia de Independência e Imparcialidade}

A independência está atrelada à imparcialidade, mas com esta não se confunde, conforme entendimento de Rocha (1995).

Independência e imparcialidade, embora conceitos conexos, eis que servem ao mesmo valor de objetividade do julgamento, no entanto têm significações diferentes. Enquanto a imparcialidade é um modelo de conduta relacionado ao momento processual, significando que o juiz deve manter uma postura de terceiro em relação às partes e seus interesses, devendo ser apreciada em cada processo, pois, só então é possível conhecer a identidade do juiz e das partes e suas relações, a independência é uma nota configuradora do estatuto dos membros do Poder Judiciário, referente ao exercício da jurisdição em geral, significando ausência de subordinação a outros órgãos. (ROCHA, 1995, p. 30)

O autor, quando define a imparcialidade como um modelo de conduta relacionado ao momento processual, traz luz a sua relação fundamental com o processo justo.

Não há como se pensar em decisão justa quando quem tem competência para tanto possui manifesto apreço prévio pelos argumentos de somente uma das partes. A parte adversa não conseguirá percebê-lo como julgador, mas sim como argumentador adicional.

Mas não é só isso.

A mesma parte também não conseguirá visualizar um efetivo julgador se ele não for coerente nos seus argumentos, ou seja, demonstrar suas convicções, mas decidir de forma diversa com fundamento em uma norma existente, por exemplo. 
Além disso, não há como ignorar que a ausência de independência de um julgador pode influenciar sobremaneira a sua decisão.

Todo ser humano tem posicionamento a respeito de um tema que lhe é afeto. Com um julgador não há que ser diferente. Exigir que se separe sua função da sua cultura seria impróprio.

Frise-se que a decisão de um julgador sempre terá influência de sua visão pessoal sobre o caso concreto. Não é razoável exigir que ele esqueça todas as suas convicções sobre um tema antes de abordá-lo em um litígio.

Exatamente por isso, é natural que de uma norma complexa possam surgir interpretações variadas a partir da intelecção do julgador. Todas essas interpretações passam pelo "filtro pessoal" dele e terão resultados de acordo com seus preceitos a respeito do tema.

É o "poder criativo" necessário à interpretação de uma norma.

Esse poder, que tem relação direta com a independência do julgador, acaba por permitir que a busca pela justiça seja constantemente renovada e aprimorada.

Relacionam-se, assim, neste ponto, as três características fundamentais para o trabalho de um julgador: a busca pela justiça, a sua independência e a sua imparcialidade.

A ausência de quaisquer dessas características não impedirá o surgimento de uma decisão, mas certamente causará, em pelo menos uma das partes em litígio, a sensação de que não houve um efetivo julgamento.

Importante relembrar que o presente trabalho não tem como objetivo a análise de garantias e características dos juízes (poder jurisdicional), mas sim a das pessoas com a função de julgar, ainda que extrajudicialmente, motivo pelo qual será abordado adiante a busca pela justiça dentro da administração pública.

\subsection{Justiça Administrativa}

Inicialmente, é imperativo conceituar a terminologia utilizada no presente texto: a expressão "justiça administrativa' se relaciona com a estrutura (orgânica e funcional) da administração pública (não jurisdicional) necessária para o julgamento de litígios surgidos em "contenciosos administrativos". 
Estes contenciosos são considerados inaugurados com as reclamações ou impugnações de um administrado em relação a um ato administrativo tendente a atingir seus direitos individuais.

Considerando que a previsão de um devido processo legal na vigente Carta Constitucional abrange também o contencioso administrativo (art. $5^{\circ}$, incisos LIV e LV da CRFB, in verbis), há que se analisar a presença de imparcialidade das autoridades competentes para o julgamento, bem como a existência de garantias para sua independência.

Art. $5^{\circ}$ Todos são iguais perante a lei, sem distinção de qualquer natureza, garantindo-se aos brasileiros e aos estrangeiros residentes no País a inviolabilidade do direito à vida, à liberdade, à igualdade, à segurança e à propriedade, nos termos seguintes:

$[\ldots]$

LIV - ninguém será privado da liberdade ou de seus bens sem o devido processo legal;

LV - aos litigantes, em processo judicial ou administrativo, e aos acusados em geral são assegurados o contraditório e ampla defesa, com os meios e recursos a ela inerentes;

Essa presença da imparcialidade pode ser observada na Lei Geral do Processo Administrativo (Lei $\mathrm{n}^{\circ}$ 9784/99 - LGPA), a qual, apesar de regular o processo administrativo em âmbito federal, aplica-se de forma subsidiária, no caso da existência de lei específica, a todo processo administrativo.

Assim como a Carta Magna, a LGPA não traz o conceito explícito de imparcialidade, limitando-se a demonstrar comportamentos impróprios para a autoridade competente chegar a um julgamento justo. Tais comportamentos são considerados impedimentos pela lei citada, in verbis:

Art. 18. É impedido de atuar em processo administrativo o servidor ou autoridade que:

I - tenha interesse direto ou indireto na matéria;

II - tenha participado ou venha a participar como perito, testemunha ou representante, ou se tais situações ocorrem quanto ao cônjuge, companheiro ou parente e afins até o terceiro grau;

III - esteja litigando judicial ou administrativamente com o interessado ou respectivo cônjuge ou companheiro.

Porém, o legislador infraconstitucional não acompanhou a lógica do constituinte em relação à previsão de garantias de independência, criando um ambiente propenso a falhas no que se refere ao cumprimento do devido processo legal em sede administrativa. 
Sabe-se impróprio alegar que nenhum órgão da justiça administrativa consegue chegar a uma decisão justa, mas tão imprópria é a alegação de que todos os julgamentos em sede administrativa serão pautados pela imparcialidade.

Como seria possível garantir a imparcialidade de um julgador que pode ter sua lotação alterada de acordo com sua decisão? Ou ainda ser considerado inapto para jugar? Ou ainda ter um aumento nos custos de moradia e deslocamento, por exemplo, decorrente dessa alteração de lotação, gerando efetiva redução do valor disponível dos seus vencimentos?

Ausentes as garantias de independência de um julgador teremos julgamentos não necessariamente justos.

Decorrente disso, surge a percepção de que um processo administrativo não é capaz de chegar a um resultado justo, tendo como efeito principal uma crise de confiança na autoridade administrativa competente.

Essa percepção pode ser oriunda dos administrados, quando sequer acionam a estrutura existente da Administração Pública para um contencioso administrativo, por entendê-la inócua.

Também pode ser oriunda do próprio Estado, quando relativiza um dos atributos do ato administrativo, a auto executoriedade ${ }^{3}$, e determina, via normatização, que a execução fiscal só seja possível em sede jurisdicional.

Nesse sentido, dados foram apresentados no artigo de Perlingeiro (2015, p. 294-295), O devido processo legal administrativo e a tutela judicial efetiva: um novo olhar?

O Judiciário brasileiro está sobrecarregado. De 83,4 milhões de feitos em 2009, atingiu a marca de 92,2 milhões em 2012, total de que 28,2 milhões (31\%) eram casos novos e 64 milhões (69\%) encontravam-se pendentes de anos anteriores. Ainda em 2012, todo magistrado sentenciou, em média, 1.450 processos, 1,4\% a mais que em 2011. Embora os magistrados julguem mais processos a cada ano, o aumento do total de sentenças (1 milhão - 4,7\%) foi inferior ao aumento de casos novos (2,2 milhões - 8,4\%), o que resultou no julgamento de $12 \%$ de processos a menos que o total ingressado. (PERLINGEIRO, 2015, p. 294-295)

\footnotetext{
${ }^{3}$ Atos administrativos podem ser executados pela Administração Pública, sem a interferência de qualquer outro Poder.
} 
O autor também demonstra que a sobrecarga do judiciário tem parcela expressiva de processos de execuções fiscais:

Não há como precisar o percentual das causas que envolvem autoridades públicas, porém estima-se que seja a maioria, acima de

50\%. Há quatro dados que levam a essa conclusão: (a) em 2012, do total de 64 milhões de processos pendentes de anos anteriores, $39,9 \%$

eram de execuções fiscais, ao passo que, em 2013, dos 66,7 milhões pendentes, 41,4\% consistiam em execuções fiscais; (b) nos últimos 20

anos, dos $90 \%$ do total dos processos judiciais em curso no Supremo Tribunal Federal/STF (Corte Constitucional), consta a presença de autoridades públicas como uma das partes; (c) dos 693 processos com repercussão geral no STF, 498 deles, isto é, 71\%, versavam sobre direito público (direito administrativo, tributário e previdenciário); (d) dos 721 recursos de efeito repetitivo no Superior Tribunal de Justiça/STJ (Corte Suprema), 360 dizem respeito a direito público, o que corresponde, portanto, a 50\% do total. (PERLINGEIRO, 2015, p. 295)

Perlingeiro expressa, assim, seu entendimento quanto às insatisfações em relação aos processos judiciais:

\begin{abstract}
No que concerne aos processos judiciais envolvendo autoridades administrativas, as insatisfações partem de todos os lados. Os interessados reclamam da morosidade e da falta de efetividade das decisões judiciais, notadamente quanto à sua qualidade e à execução forçada de decisões e medidas cautelares contra autoridades públicas. Por sua vez, as autoridades alegam que os juízes interferem indevidamente nos Poderes Discricionários, com ofensa ao princípio da separação de Poderes, e que proferem decisões judiciais sem considerar que as autoridades administrativas devem observar a necessidade de tratamento igualitário em relação a todos os interessados, ainda que não sejam demandantes judiciais (PERLINGEIRO, 2015, p. 295)
\end{abstract}

Esses dados trazem luz a um dos marcantes efeitos da crise de confiança já citada, qual seja a tendência ao esgotamento da capacidade do poder judiciário para prestar a tutela jurisdicional, ainda que seus profissionais tenham, progressivamente, aumentado o número de decisões.

Além disso, há outra forma de o Estado manifestar a percepção de que um processo administrativo não é capaz de chegar a um resultado justo, qual seja a existência de decisões jurisdicionais no sentido de fazer uma total revisão de mérito de um ato administrativo.

Tal efeito parece vir reforçar a necessidade de revisão da atual estrutura de garantias de independência do julgador administrativo. 


\section{CONSIDERAÇÕES FINAIS}

O presente trabalho demonstrou como a evolução histórica do conceito de justiça alterou sensivelmente a função de um julgador, bem como orientou o surgimento de normas para garantir sua função.

Atualmente, a Carta Magna traz garantias ao juiz (poder jurisdicional), por meio das regras contidas nos seus artigos 95 e 99.

Essas garantias são classificadas, segundo a melhor doutrina, como institucionais ou funcionais. Dentre as funcionais encontram-se as de independência e algumas de imparcialidade.

O legislador infraconstitucional também seguiu o mesmo cuidado do constituinte em relação à busca de um julgamento imparcial, porém não acompanhou a lógica do constituinte em relação à previsão de garantias de independência, acabando por criar um ambiente propenso a falhas no que se refere ao cumprimento do devido processo legal em sede administrativa.

O julgador administrativo, nesse ambiente, passa a considerar seus receios no momento de decidir, lembrando da possibilidade que do resultado de seu trabalho possa decorrer a alteração de sua lotação, a declaração de sua inaptidão para o julgamento ou ainda ter uma efetiva redução do valor disponível dos seus vencimentos.

Entende-se, assim, que a hipótese pela impossibilidade de garantir um julgamento imparcial em um ambiente de ausência de garantias de independência para o julgador foi confirmada, uma vez que o resultado de sua função na administração pública sempre passará por uma espécie de "filtro pessoal", sendo impróprio exigir que ele esqueça dos efeitos potencialmente negativos de sua decisão.

A solução mais efetiva para a busca da imparcialidade no julgamento de um processo administrativo parece ser a edição de legislação que traga garantias à autoridade competente para decidir em contenciosos administrativos.

Tal legislação pode prever o estabelecimento de garantias de independência tanto para julgadores em uma estrutura funcional similar à existente ou em um novo órgão autônomo.

Há que se considerar, porém, que a garantia de independência para julgadores em uma estrutura funcional similar à existente pode resultar na diversidade de decisões em relação a uma mesmo tema, situação que pode ressaltar uma aparente colisão entre 
princípios administrativos, quais sejam o princípio da imputação volitiva (Teoria do Órgão) $)^{4}$ e o princípio da Autotutela Administrativa.

Considerando, ainda, que possa existir uma resistência política à regulamentação das garantias à autoridade competente para decidir em contenciosos administrativos, também parece possível a adoção de duas outras soluções, ainda que provisórias.

Uma delas seria a obrigatoriedade de as decisões seguirem jurisprudência pacífica de tribunais superiores, ainda que não presentes a repercussão geral ${ }^{5}$ ou o efeito repetitivo $^{6}$, reduzindo a possibilidade de decisões potencialmente reformadas em sede jurisdicional.

A outra seria a utilização da mediação, com vistas a obter acordos entre as partes (fim do contencioso) ou um parecer técnico, imparcial e embasado do mediador, sugerindo uma decisão para a autoridade competente.

\footnotetext{
4 A teoria do órgão enuncia que toda atuação do agente público deve ser imputada ao órgão que ele representa e não à sua pessoa. Por consequência, sendo o órgão uma divisão das pessoas que compõe a Administração Pública direta ou indireta, a atuação dos servidores públicos é atribuída diretamente à pessoa jurídica para a qual trabalha.

5 Tem por finalidades a delimitação da competência do STF, no julgamento de recursos extraordinários, às questões constitucionais com relevância social, política, econômica ou jurídica, que transcendam os interesses subjetivos da causa, bom como a uniformização da interpretação constitucional sem exigir que o STF decida múltiplos casos idênticos sobre a mesma questão constitucional.

6 O recurso especial repetitivo implantado no Superior Tribunal de Justiça trata do julgamento dos casos em que haja multiplicidade de recurso com fundamento em idêntica questão de direito. O Presidente do

Tribunal de origem admitirá um ou mais recursos representativos da controvérsia, os quais serão encaminhados ao STJ, ficando os outros sobrestados até a solução da pendência.
} 


\section{REFERÊNCIAS}

BRASIL. Constituição (1824). Constituição Política do Império do Brazil (de 25 de março de 1824). Portal da Legislação: Constituições. 1824. Disponível em:

$<$ http://www.planalto.gov.br/ccivil_03/Constituicao/Constituicao24.htm>. Acesso em: 30 mar 2016.

Constituição (1891). Constituição da República dos Estados Unidos do Brasil (de 24 de fevereiro de 1891). Portal da Legislação: Constituições. 1891. Disponível em: <http://www.planalto.gov.br/ccivil_03/Constituicao/Constituicao91.htm>. Acesso em: 30 mar 2016.

Constituição (1934). Constituição da República dos Estados Unidos do Brasil (de 16 de julho de 1934). Portal da Legislação: Constituições. 1934. Disponível em: <http://www.planalto.gov.br/ccivil_03/Constituicao/Constituicao34.htm>. Acesso em: 30 mar 2016;

Constituição (1988). Constituição da República Federativa do Brasil: promulgada em 5 de outubro de 1988. Portal da Legislação: Constituições. 1988. Disponível em: <http://www.planalto.gov.br/ccivil_03/Constituicao/Constituicao.htm>. Acesso em: 30 mar 2016.

Decreto-Lei no 4.657, de 4 de setembro de 1942. Lei de Introdução às normas do Direito Brasileiro. Portal da Legislação: Decretos-Leis. 1942. Disponível em: $<$ http://www.planalto.gov.br/ccivil_03/decreto-lei/Del4657compilado.htm>. Acesso em: 30 mar 2016;

Lei $\mathbf{n}^{\mathbf{0}}$ 9.784, de 29 de janeiro de 1999. Regula o processo administrativo no âmbito da Administração Pública Federal. Portal da Legislação: Leis Ordinárias. 1999. Disponível em: <http://www.planalto.gov. br/ccivil_03/leis/L9784.htm>. Acesso em 30 mar 2016.;

CAMPANELLI, Luciana Amicucci. Poderes Instrutórios do Juiz e a Isonomia Processual. São Paulo: Juarez de Oliveira, 2006.

FERRAZ JR, Tercio Sampaio. Introdução ao Estudo do Direito: Técnica, Decisão, Dominação. 4. ed. São Paulo: Atlas, 2003.

FIGUEIRA, Divalte Garcia. História. São Paulo: Ática, 2002.

FREITAS FILHO, Roberto. Crise do Direito e Juspositivismo: A Exaustão de um Paradigma. Brasília: Brasília Jurídica, 2003, p. 40-41.

FREITAS, Juarez. O Controle dos Atos Administrativos e os Princípios

Fundamentais. $3^{\text {a }}$ Ed. São Paulo: Malheiros, 2004. 
KELSEN, Hans. Teoria Pura do Direito. (Tradução: João Baptista Machado). São Paulo: Martins Fontes, 1991.

MENDES, Gilmar Ferreira e BRANCO, Paulo Gustavo Gonet. Curso de Direito Constitucional. São Paulo: Saraiva, 2012.

MONTESQUIEU, Charles Louis de Secondat. O Espírito das Leis. Brasília: UnB, 1995, p. 118.

PACHECO, José da Silva. Curso de Teoria Geral do Processo. Rio de Janeiro: Forense, 1985.

PERLINGEIRO, Ricardo. O devido processo legal administrativo e a tutela judicial efetiva: um novo olhar?. Revista de Processo, São Paulo, v. 239, p. 293-331, Jan. 2015. Disponível em: <http://ssrn.com/abstract=2511545>. Acesso em: 30 mar 2016.

REALE, Miguel. Teoria Tridimensional do Direito. 5. ed. São Paulo: Saraiva, 1994.

ROCHA, José de Albuquerque. Estudos sobre o Poder Judiciário. São Paulo: Malheiros, 1995. p. 30

ROUSSEAU, Jean-Jacques. Do Contrato Social - Ensaio sobre a Origem das Línguas. São Paulo: Nova Cultural, 1999. (Coleção Os Pensadores, v. 1).

SILVA, José Afonso da. Curso de Direito Constitucional Positivo. 24. ed. São Paulo: Malheiros, 2005. p. 588 et seq. 